\title{
O CONTEÚDO DE SISTEMÁTICA E FILOGENÉTICA EM LIVROS DIDÁTICOS DO ENSINO MÉDIO
}

\author{
Marciel Elio Rodrigues* \\ Lourdes Aparecida Della Justina** \\ Fernanda Aparecida Meglhioratti***
}

RESUMO: É fundamental identificar as transformações nas populações de organismos ao longo do tempo e situar as linhagens com os seus representantes atuais, facilitando uma aprendizagem coerente com o conhecimento biológico atual. Por essas razões, nesse trabalho realizamos uma análise qualitativa sobre o conteúdo Sistemática e Filogenética em cinco livros didáticos recomendados pelo Programa Nacional do Livro para o Ensino Médio. Verificou-se que entre os livros analisados nenhum utiliza a filogenia como eixo integrador do ensino. Acredita-se que a filogenia, como eixo integrador, permita uma abordagem comparativa da vida, facilitando os estudos de Zoologia e Botânica e fornecendo subsídios para a compreensão da diversidade biológica voltada para uma abordagem evolutiva.

Palavras-chave: Ensino de Biologia; Filogenia; Livro Didático.

\section{THE CONTENTS OF SYSTEMATIC AND PHYLOGENETIC IN HIGH SCHOOL TEXTBOOKS}

ABSTRACT: It is essential to identify changes in populations of organisms over time and locate the lineages according to their contemporary representatives, facilitating learning consistent with current biological knowledge. Therefore, in this work we carry out a qualitative analysis on the Systematic and Phylogenetic content in five books recommended by the Programa Nacional do Livro para o Ensino Médio (National Book Program for High School). And it was found that amongst the books reviewed, none uses the phylogeny as an axis integrator of education. It is believed that the phylogeny as axis integrator allows a comparative approach of life by facilitating studies in zoology and botany and providing subsidies for the understanding of biological diversity targeted towards an evolutionary approach.

Keywords: Biology Teaching; Phylogeny; Textbook.

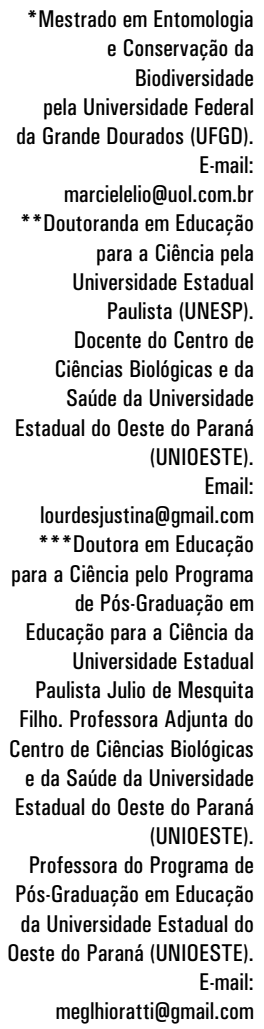

Professora do Programa de Pós-Graduação em Educação da Universidade Estadual do Oeste do Paraná (UNIOESTE).

E-mail:

meglhioratti@gmail.com 


\section{INTRODUĈ̣̃O}

O presente artigo é resultado de uma pesquisa realizada por um grupo de pesquisadores em Epistemologia da Biologia e se insere numa investigação mais ampla que envolve o estudo de conceitos biológicos e sua abordagem em diferentes contextos do ensino de Biologia. Neste artigo, buscamos contribuir para uma reflexão sobre o conteúdo biológico em livros didáticos do Ensino Médio em relação à "sistemática filogenética".

No contexto de aulas de Biologia do Ensino Médio, muitas vezes, há uma abordagem fragmentada do ensino de Biologia, na qual não se articulam os aspectos evolutivos com o estudo das estruturas e processos biológicos, o que pode estar associado à negligência do ensino de Zoologia e Botânica (AMORIM et al; 2001; KRASILCHIK, 2005). Atribui-se este fato ao caráter estritamente memorístico que acompanha estas áreas de conhecimento em livros didáticos e na concepção de professores e estudantes. Essa é uma realidade que deve ser combatida, pois os estudos de Zoologia e Botânica permitem evidenciar a diversidade dos seres vivos, sendo a sistemática ${ }^{1}$ a base para compreender a diversidade e a organização biológica (MALLET; WILMOT'T, 2003).

Na delimitação do "recorte" do conteúdo biológico para investigação, partimos da afirmação de Moore (2003) de que a ordenação sistemática dos seres vivos pode ser feita de várias formas. Porém, a mais conveniente é aquela que tem como objetivo produzir uma classificação "natural", isto é, uma filogenia ${ }^{2}$ que revele a história evolutiva. Nesse sentido, a sistemática filogenética permite aos estudantes visualizarem as relações entre os organismos e identificarem as características que unem seres vivos em determinado grupo, ou seja, possibilita identificar as características que fazem com que um grupo seja válido à luz da teoria evolutiva, sendo um grupo monofilético ${ }^{3}$ (GUIMARÃES, 2004).

Pesquisas na área de ensino de Ciências com enfoque no livro didático se justificam, conforme Freitas e Martins (2008), devido à sua penetração junto a um público leitor jovem, sendo que o livro constitui material de referência, informação e consulta sobre diversos temas para muitos alunos. Embora muitas investigações tenham focalizado a análise de livros didáticos de Ciências e Biologia nos últimos anos na temática "sistemática filogenética", acredita-se que a abordagem deste assunto mereça reflexões que apontem suas limitações e possíveis alternativas para adequação aos indicativos da pesquisa em ensino de Biologia, bem como dos avanços do conhecimento biológico.

Assim, o objetivo deste trabalho foi realizar uma análise qualitativa sobre o conteúdo de sistemática e filogenética presente em livros didáticos recomendados pelo Ministério da Educação e Cultura (MEC) por meio do Programa Nacional do Livro para o Ensino Médio - PNLEM e disponibilizados para serem utilizados por alunos do Ensino Médio em escolas públicas brasileiras.

No presente artigo, inicialmente, abordamos uma história da sistemática e filogenética, de modo breve. Em seguida, são apresentados alguns aponta- 
mentos da área de ensino da Biologia voltados ao livro didático e à sistemática filogenética. Após essa etapa são elencados e discutidos os resultados da análise de cinco livros didáticos de Biologia.

\section{BREVE HISTÓRIA DA SISTEMÁTICA FILOGENÉTICA}

Nas Ciências Biológicas, o naturalista sueco Carl Von Linnée - Lineu (1707-1778) - é considerado como o estudioso que deu origem formal à sistemática, por meio do seu sistema binominal de nomenclatura. Este sistema de classificação foi publicado nas primeiras edições de Species plantarum (1753) e na décima edição de Systema naturae (1758). O sistema de Lineu se tornou muito difundido e aceito na comunidade científica da época e, até hoje, vem sendo utilizado em materiais de divulgação científica, como é o caso dos livros didáticos. Para Lineu, o zoólogo poderia reconhecer todas as espécies de animais. Isso porque, conforme ele, não existiriam mais que alguns milhares de espécies que foram colocadas na Terra pelo "Criador" e, além disso, eram imutáveis. (DUPRÉ, 2002). As categorias taxonômicas de Lineu são insuficientes para comportar toda a diversidade conhecida e, ao longo da história da Biologia, os taxonomistas modernos têm proposto novas categorias para poder organizar a biodiversidade.

Após a publicação de $A$ origem das espécies ${ }^{4}$ muitos sistematas passaram a estudar filogenias. A árvore da vida de Haeckel, de 1866, é um ótimo exemplo dos resultados desse interesse. Porém, todo esse conhecimento era construído com base na experiência e observação do especialista. Não havia um método para inferir filogenias. Além disso, a maioria dos biólogos estava preocupada com problemas de espécie, especiação e variações geográficas e o estudo de filogenia ficou relegado ao segundo plano. Foi o botânico alemão Walter Zimmerman que, na primeira metade do século XX, apresentou uma discussão clara sobre filogenia e defendeu fortemente as classificações filogenéticas. (DONOGHUE \& KADEREIT, 1992). Na década de 1950, mesmo fazendo muitos elogios ao estudo de filogenias, muitos taxonomistas vegetais eram céticos a respeito dos sistematas serem realmente capazes de reconstruir filogenias. Estas eram ainda produzidas por uma autoridade em um dado grupo de seres vivos, sem a utilização de nenhum método explícito. Assim, poucos sistematas levavam esses esforços a sério.

Nas décadas de 1950 e 1960, dois grupos de pesquisa surgiram e cada um tratou da falta de rigor nos estudos filogenéticos, mas de modo diferente. Ambos os grupos procuravam trazer metodologias explícitas e objetivas para a sistemática. No grupo dos taxonomistas numéricos afirmava-se que seria impossível reconhecer as filogenias e utilizava-se a similaridade geral como critério de classificação. O primeiro livro deste grupo foi o princípio da taxonomia numérica (The principles of numerical taxonomy), escrito por Robert R. Sokal e Peter H. A. 
Sneath, em 1950. O outro grupo de pesquisa seguiu as linhas que Walter Zimmerman e outros filogeneticistas tinham começado a desenvolver. Este autor defendia que a filogenia deveria ser o princípio organizador central em sistemática e ao buscar metodologias objetivas e confiáveis poder-se-ia inferir filogenias. Um dos autores mais influentes a desenvolver tais metodologias foi Willi Hennig, em 1950. Seu livro foi escrito em alemão e traduzido para o inglês em 1966, por isso suas ideias demoraram a ser difundidas pelo mundo (HULL, 2001). Pessoas que concordavam com Hennig, que a filogenia deveria ser central para a sistemática, que filogenias poderiam ser construídas a partir de comparação com espécies existentes e que as classificações deveriam ser baseadas diretamente na filogenia foram chamadas por Mayr (1998) de Cladistas (clados = ramo). Da mesma forma, os taxonomistas numéricos foram chamados por Mayr (1998) de feneticistas (fenos $=$ aparência), por se preocuparem com similaridades gerais entre as espécies.

Outro grupo de sistematas também apareceu na década de 1960. Biólogos moleculares, que nunca estiveram envolvidos diretamente nos debates sobre filosofia sistemática, se interessaram em inferir filogenias utilizando seus dados moleculares. Para eles, a filogenia era a chave para entender não somente a história evolutiva dos táxons, mas também os detalhes da evolução dos genes. Era óbvio, portanto, que técnicas quantitativas e inferência filogenética eram partes críticas da sistemática, embora muitos sistematas moleculares tivessem pouco interesse na conexão entre filogenia e classificação ou apreciassem o desenvolvimento de uma teoria da sistemática. (HULL, 1988).

Na década de 1980, embora as batalhas continuassem a ser disputadas entre os vários grupos de pesquisa ou seus remanescentes, os velhos rótulos começaram a ficar sem sentido. Se, por cladista, tinha-se em vista um sistemata que considerava a inferência da filogenia como de grande importância, acreditava-se que classificações deveriam ser baseadas diretamente nas filogenias inferidas e adotava-se pelo menos alguma terminologia cladística, assim a vasta maioria dos sistematas era cladista. Por outro lado, praticamente todos os sistematas na década de 1980 julgavam o uso de computadores e técnicas quantitativas essenciais para seu trabalho. Nesse sentido, taxonomistas numéricos tiveram sucesso. Se forem usadas definições mais restritivas, tais como requerer que somente a metodologia original de Hennig seja usada para ser chamado um cladista, ou, que classificações sejam baseadas estritamente em similaridades,para ser chamado feneticista, então, os dois grupos mudaram muito nas últimas décadas. (HULL, 1988).

Todos os sistematas atuais usam ferramentas filogenéticas. Já existe um número significativo de obras específicas sobre cladismo, uma das quais produzida no Brasil: Fundamentos de sistemática filogenética, de Dalton S. Amorim (2005). Livros-texto universitários novos e reedições de obras consagradas inserem conceitos cladísticos no seu conteúdo. Muito recentemente, alguns livrostexto de Ensino Médio e fundamental passaram a apresentar essa metodologia, 
muito embora, de modo pouco convincente, porque os autores insistem em manter a sequência do desenvolvimento do conteúdo segundo a sistemática tradicional. Acredita-se que, uma mudança, no sentido de inclusão da abordagem cladística seja imprescindível para a melhoria do ensino de Biologia que deve começar pelos livros universitários e chegar aos livros didáticos da Educação Básica nos próximos anos.

\section{0 LIVRO DIDÁTICO E A SISTEMÁTICA FILOGENÉTICA NO ENSINO MÉDIO}

No Brasil, algumas tentativas de introduzir o ensino de Sistemática Filogenética na Educação Básica têm ocorrido no Ensino Médio (AMORIM, 2005; AMORIM et al, 2001; LOPES; FERREIRA \& STEVAUX, 2007) e fundamental (SCHUCH \& SOARES, 2003) com ótimas perspectivas de ensino, quando utilizadas como eixo centralizador da discussão da biodiversidade. Também há uma grande preocupação em divulgar a sistemática filogenética em cursos de graduação.

A introdução da sistemática filogenética no Ensino Médio contribui diretamente para o ensino dos seres vivos, como Zoologia e Botânica. Porém, outros tópicos poderiam ser abordados, tais como a evolução do comportamento e a evolução dos sistemas do corpo relacionada ao meio. A vantagem do uso da sistemática filogenética seria, em princípio, a de permitir uma abordagem comparativa da vida e diminuir a distância entre os grupos de seres vivos. (GUIMARÃES, 2005).

A sistemática filogenética poderia facilitar os estudos de Zoologia e Botânica fornecendo subsídios para a compreensão da diversidade biológica (AMORIM, 1997) e permitindo, mediante o conhecimento do aparecimento de determinados caracteres na evolução biológica, a compreensão de grupos de seres vivos que compartilham as mesmas características. Dessa forma, a estratégia de ensinar sobre os seres vivos por meio de aspectos filogenéticos evita a memorização dos caracteres dos grupos, facilitando a integração entre os conceitos biológicos.

Quando o aluno memoriza caracteres, sem uma relação evolutiva, caracteriza-se por um pensamento essencialista, sendo este, em parte, responsável pelo caráter enfadonho do ensino de Zoologia e Botânica, como apontado por Amorim et al (2001). Aliás, era ideia de Lineu que os estudiosos da fauna e da flora deveriam ser capazes de memorizar todos os caracteres de todos os grupos (ERESHEFSKY, 1997), o que é impossível, reconhecida a biodiversidade atual. Em um contexto essencialista, o que se busca são os caracteres, ou essências, que permitem diferenciar os grupos. A sistemática filogenética, por outro lado, procura os caracteres compartilhados devido a uma ancestralidade comum. Isso permite mostrar aos estudantes que existe uma continuidade na vida. Os seres vivos não se apresentam na natureza como estão nos livros didáticos, de 
forma linear, ou seja, somente como uma forma de ordenar os seres vivos, sem qualquer conotação evolutiva.

Com os trabalhos de Hennig (1966; 1975), os seres vivos deixam de ser vistos de forma isolada e os caracteres deixaram de ser vistos como sendo exclusivos de cada grupo. Como ressalta Guimarães (2005), falta agora permitir que esta visão atinja a Educação Básica para que a revolução vista na Biologia como Ciência também seja vista na Biologia como disciplina escolar.

Essa mudança deve perpassar o livro didático utilizado pelo professor em determinado momento do contexto escolar para contemplar certos objetivos educacionais. Também o livro didático pode ser utilizado como material de apoio ao aluno para realização de trabalhos e atividades. No entanto, algumas pesquisas realizadas nas últimas duas décadas têm apontado que o livro didático tem, muitas vezes, funcionado como um guia para o trabalho a ser desenvolvido, destituindo o papel do professor na seleção e organização dos conteúdos a serem trabalhados. (GIANNOTTI, 2002; MOREIRA \& ATX, 1991). Conforme foi crescendo a popularidade dos livros didáticos, cresceu também a preocupação com sua qualidade, uma vez que já era apontado por Francalanza, Amaral e Gouveia (1986), como um dos recursos mais utilizados no ensino.

Hoje, o livro didático possui uma presença marcante em salas de aula e isto se deve ao fato de ser um dos principais materiais impressos a que os alunos e professores de escolas brasileiras têm acesso. Este processo é reforçado pelos Governos dos Estados que têm adquirido e distribuído este material em massa. Desta forma, para muitos professores e alunos, o livro didático torna-se um modelo de ensino e sua qualidade e mesmo a sua colocação nesta função não é questionada. (BATISTETI et al, 2007). O professor deve analisar o livro a ser adotado não só para verificar a existência de erros, mas também para verificar se os objetivos do autor e os seus objetivos são os mesmos. (ALVARES, 1991). Também cabe considerar que o professor deve refletir sobre como os textos e as atividades do livro didático podem ser utilizadas para abordar os conteúdos e objetivos que estão em seu plano de ensino e não ao contrário, utilizando o livro como um roteiro para selecionar conteúdos e objetivos de ensino.

Segundo o Programa Nacional do Livro para o Ensino Médio PNLEM (2009), o livro destinado ao Ensino Médio tem múltiplos papéis, entre os quais se destacam: (i) favorecer a ampliação dos conhecimentos adquiridos ao longo do Ensino Fundamental; (ii) oferecer informações capazes de contribuir para a inserção dos alunos no mercado de trabalho, o que implica a capacidade de buscar novos conhecimentos de forma autônoma e reflexiva e (iii) oferecer informações atualizadas, de forma a apoiar a formação continuada dos professores. Por essas razões, a escolha do livro deve ser criteriosa e afinada com as características da escola, dos alunos e com o contexto educacional em que estão inseridos.

Nos Parâmetros Curriculares Nacionais - PCNs, os currículos para o ensino de Ciências Naturais estão atrelados ao sistema "lineano" de classificação 
biológica (BRASIL, 2002). O sistema criado por Lineu, em 1758, está baseado em ideias criacionistas. Nessa perspectiva, as unidades biológicas (espécies) são entidades independentes e imutáveis. É um método catalográfico obsoleto e incoerente com as bases evolucionistas adotadas pelo atual sistema educacional. (LOPES et al, 2004).

Concordando com Lopes, Ferreira e Stevaux (2007), para promover um ensino/aprendizado coerente em Biologia, em especial na área da sistemática e taxonomia, é necessário entender a dinâmica da vida orientada pelo processo evolutivo. É fundamental identificar as transformações em populações de organismos ao longo do tempo e situar as linhagens com representantes atuais, reconhecendo diferenças entre os seres vivos e as semelhanças que oferecem identidade e unidade aos sistemas biológicos.

$\mathrm{Na}$ pesquisa em ensino de Biologia há o reconhecimento de que o livro didático é um dos principais recursos utilizados tanto por professores como por alunos como fonte de informações sobre o conhecimento biológico no Ensino Médio. Também, considerando a importância do tema em questão para o ensino de Biologia, na sequência é descrito o percurso da investigação de conteúdo acerca de sistemática e filogenética em livros da disciplina de Biologia do Ensino Médio.

\section{METODOLOGIA DA PESQUISA}

Este trabalho visou à análise qualitativa de livros didáticos utilizados na rede pública de ensino. Para isso, foram escolhidos cinco livros que estão aprovados pelo Programa Nacional do Livro do Ensino Médio - PNLEM.

$\mathrm{O}$ desenvolvimento da pesquisa de cunho qualitativo ocorreu com base no método de análise de conteúdo. Segundo Bardin (2000), este método envolve um conjunto de técnicas de análise das comunicações entre os homens, dentre elas, a da linguagem escrita, por que estas são mais estáveis e constituem um material objetivo o qual podemos consultar quantas vezes forem necessárias. A análise de conteúdo se constituiu em: pré-análise e separação dos livros a serem analisados; exploração do material selecionado e tratamento dos resultados; e, inferência e interpretação.

Os livros escolhidos para realização do trabalho são apresentados no Quadro 1. 
Quadro 1 - Livros didáticos utilizados para elaboração do trabalho e como os mesmos serão abordados no decorrer do texto.

\begin{tabular}{|c|c|c|c|c|c|}
\hline Título & $\begin{array}{l}\text { Fundamentos da } \\
\text { Biologia Moderna }\end{array}$ & $\begin{array}{c}\text { Biologia - } \\
\text { volume único }\end{array}$ & $\begin{array}{c}\text { Biologia - } \\
\text { volume único }\end{array}$ & $\begin{array}{c}\text { Biologia - } \\
\text { volume único }\end{array}$ & $\begin{array}{l}\text { Biologia - } \\
\text { volume único }\end{array}$ \\
\hline Autores & $\begin{array}{c}\text { José Mariano Amabis } \\
\text { \& Gilberto Rodrigues } \\
\text { Martho }\end{array}$ & J. Laurence & $\begin{array}{l}\text { Sônia Lopes \& } \\
\text { Sergio Rosso }\end{array}$ & $\begin{array}{c}\text { Sérgio Linhares \& } \\
\text { Fernando } \\
\text { Gewandsznajder }\end{array}$ & $\begin{array}{l}\text { José Arnaldo Favaretto } \\
\& \text { Clarinda Mercadante }\end{array}$ \\
\hline Ano & 2006 & 2005 & 2005 & 2005 & 2005 \\
\hline Edição & $4^{\mathrm{a}}$ edição & $1^{\mathrm{a}}$ edição & $1^{\text {a }}$ edição & $1^{\text {a }}$ edição & $1^{\text {a }}$ edição \\
\hline Representação & Livro A & Livro B & Livro C & Livro D & Livro $\mathrm{E}$ \\
\hline
\end{tabular}

Todos os livros analisados constituíam-se em volume único, portanto, utilizados para as três series do Ensino Médio. A análise dos conteúdos relacionados à sistemática e filogenética presentes nos livros didáticos foi realizada mediante uma ficha de avaliação de livros didáticos (Quadro 2) adaptada dos trabalhos de Lima (1984) e Silva, Alves e Gianotti (2006) e da avaliação utilizada no PNLEM (2009).

Como parâmetro na análise de conteúdos dos livros didáticos, utilizamos o livro-texto Fundamentos de sistemática filogenética, de Dalton S. Amorim, publicado em 2005. Os procedimentos de análise constituíram-se primeiramente em uma leitura minuciosa dos capítulos referentes ao assunto, no qual foi investigado o conjunto de capítulos referente aos "Seres vivos", por se tratarem de capítulos que abordam o assunto de sistemática e filogenética.

Quadro 2 - Ficha de avaliação com os critérios utilizados para elaboração do trabalho.

\begin{tabular}{c|l} 
1. Conteúdo teórico & $\begin{array}{l}\text { Presença de informações } \\
\text { Definições apresentadas no texto }\end{array}$ \\
\hline 2. Abordagem do conteúdo & $\begin{array}{l}\text { Presença de contextualização } \\
\text { Presença de problematização }\end{array}$ \\
\hline 3. Atividades propostas & $\begin{array}{l}\text { Disposição das atividades propostas ao longo do capítulo e/ou unidade } \\
\text { Quais habilidades cognitivas as atividades possibilitam que o aluno desenvolva }\end{array}$ \\
\hline 4. Uso de imagens & $\begin{array}{l}\text { Disposição das imagens ao longo do capítulo e/ou unidade } \\
\text { Presença de legenda nas imagens }\end{array}$ \\
& $\begin{array}{l}\text { Relação da imagem com o conteúdo abordado no texto } \\
\text { Possibilidade de distorções conceituais pelo uso de imagens }\end{array}$ \\
\hline 5. Abordagem da História da Ciência & Presença da História e Filosofia da Ciência
\end{tabular}

Para a análise do conteúdo teórico, o primeiro aspecto evidenciado foi a presença de informações a respeito do tema. Quando essa informação estava presente, buscamos responder as seguintes questões: a informação está condizente com o conhecimento científico atual? Como o conteúdo está sendo abordado no decorrer do texto? São definidos os termos utilizados no decorrer do texto?

$\mathrm{Na}$ análise da abordagem do conteúdo, verificamos como ele é desenvolvido, se existe contextualização e/ou problematização no texto do livro didático, pois são esses fatores que contribuem para a construção do conhecimento 
do estudante. Nas atividades propostas, buscamos verificar se os livros sugerem atividades complementares, como projetos, pesquisas, jogos, entre outros. Também, se fornecem subsídios para a correção das atividades e exercícios propostos aos alunos. Verificamos a presença de imagens e figuras nos textos, como estão disponibilizadas e se permitem um maior entendimento do conteúdo abordado e também a utilização de legendas nas tabelas e figuras. Analisamos também a abordagem histórica do assunto em questão. De acordo com Martins (1990), a história da Ciência, muitas vezes é ignorada ou distorcida nos livros didáticos.

\section{RESULTADOS E DISCUSSÃO}

Em cada livro foram analisados os capítulos correspondentes aos seres vivos. Como podemos observar, em geral, no início de cada unidade há um capítulo introdutório aos sistemas de classificação. Neste, os autores enfatizam diretamente a sistemática e filogenética, não levando, muitas vezes, a discussão para os outros capítulos da unidade. Desse modo, não sustentam na discussão sobre os seres vivos, a filogenia como um eixo centralizador, conforme Amorim (1997), o que forneceria melhores subsídios para a compreensão da diversidade biológica.

\subsection{Conteúdo teórico}

No livro A foi analisada a terceira unidade "Classificação biológica e os seres mais simples". Quanto à análise do conteúdo teórico, a unidade analisada apresenta um capítulo denominado de "Sistemática e classificação biológica", no qual aborda o assunto de forma clara, com textos, figuras e explicações sobre cada conceito, mostrando a sistemática tradicional e a filogenética. Por exemplo, aborda os conceitos de sistemática, árvores filogenéticas e cladística explicando cada um deles de forma coerente, quando comparados com as definições dadas por Amorim (2005). Salienta-se que essa abordagem e discussão estão restritas ao capítulo introdutório do livro analisado.

Em análise do livro B, percebe-se que a quarta unidade corresponde à temática intitulada "Os seres vivos", abordando o assunto no capítulo "Os seres vivos e os vírus". O enfoque é superficial dando maior ênfase na sistemática tradicional, não levando em conta a sistemática moderna, apresentando somente uma página com o tema de forma bem discreta.

O livro C, no capítulo "Introdução aos estudos dos seres vivos", apresenta aos leitores a importância da sistemática e filogenética para o ensino, explicitando de forma clara, conteúdos tais como: noções de sistemática, sistemática evolutiva e filogenética, construções de cladograma e modificações constantes na área da sistemática. 
Ao analisar o livro D, verificamos que a quarta unidade denominada "A diversidade da vida" traz o tema abordado. Os autores fazem uma apresentação num capítulo introdutório sobre os sistemas de classificação citando nomes de autores importantes que contribuíram para os sistemas de classificações como Lineu e Charles Darwin, situando as ideias sobre a taxonomia proposta por Lineu e a filogenia de Darwin pela evolução.

Quanto ao livro E, a segunda unidade intitulada "Bases biológicas da classificação" aborda, em quase toda sua extensão, a sistemática taxonômica dos seres vivos de uma forma explícita com vários esquemas e figuras autoexplicativas, mas não cita em nenhum momento a classificação filogenética dos organismos.

Como podemos notar, todos os livros apresentam um capítulo sobre os sistemas de classificação biológica, mas somente os livros A, C e D abordam o conteúdo de sistemática e filogenética de forma clara, com informações e definições no decorrer do texto, demonstrando a importância da abordagem e discussão da temática em sala de aula, com um enfoque maior nos capítulos introdutórios.

\subsection{Abordagem do conteúdo}

Retratando a abordagem do conteúdo, o livro A apresenta uma forma clara de expor os assuntos seguindo uma divisão de títulos e subtítulos, colocando as palavras principais em cores distintas, com os seus significados, com figuras para representar as escritas, recorre à história quando necessário e coloca exemplos que chamam a atenção do aluno para o conteúdo. A sistemática filogenética é abordada de forma dinâmica e que facilita a leitura, contextualizando e problematizando o assunto no decorrer do capítulo introdutório. Já o livro B não chama a atenção do aluno com exemplos. Os textos são descontextualizados, abordando somente o sistema de classificação tradicional.

O livro C aborda a temática no decorrer do texto, dividido com subtítulos, focando a diversidade dos seres vivos e mostrando o porquê e a importância da classificação dos seres vivos. Também são enfocadas noções de sistemática e sistemática evolutiva e filogenética. As palavras-chave estão em negrito no decorrer do texto e a sua definição está de acordo com o apresentado por Amorim (2005). Por exemplo: “[...] são chamados monofiléticos os grupos que incluem um ancestral e todos seus descendentes (mono= um, único)". (LOPES \& ROSSO, 2005, p. 183). O livro apresenta, ainda, os passos para a construção de cladogramas.

Com base no estudo comparado, a sistemática filogenética procura definir para cada caráter qual é a condição primitiva, que ocorre em um ancestral, e qual é a condição deriva$d a$, que surge a partir da primitiva. (LOPES; ROSSO, 2005, p. 183) 
Nos cladogramas, a base de onde partem os ramos é chamada raiz, e os grupos de seres vivos são colocados no ápice, compondo os terminais. Os pontos de onde partem as ramificações são chamados de nós e representam ancestrais comuns [...]. (LOPES \& ROSSO, 2005, p. 183)

No livro D, as palavras de cunho científico no decorrer do texto são desmembradas e são conceituadas entre parênteses para que os alunos possam entender o que está colocado. A abordagem do conteúdo é feita tentando chamar a atenção do aluno para o grande número de espécies existentes no planeta e do porquê dessa diversidade, com enfoque evolutivo:

As relações filogenéticas entre os grupos de seres vivos são apresentadas na forma de árvores filogenéticas ou cladogramas (do grego, clados $=$ ramo). $\mathrm{Na}$ árvore, as bifurcações (chamadas "nós") indicam espécies ancestrais [...]. (LINHARES \& GEWANDSZNAJDER, 2005, p. 141).

O livro E não apresenta uma discussão sobre sistemática e filogenética, enfatizando somente a classificação tradicional. Como já verificamos no subitem anterior, os livros B e E se eximem de abordar a temática, o que não impediu de encontrarmos no decorrer dos capítulos algumas atividades e figuras sobre a sistemática filogenética.

\subsection{Atividades propostas}

O livro A apresenta atividades diversas que remetem à sistemática filogenética. Ao final e no decorrer dos outros capítulos são apresentadas questões objetivas e dissertativas que levam o aluno a ter a oportunidade de investigação e associação do conteúdo estudado, como no caso da Figura 1.

Figura 1 - Atividade com abordagem da filogenia (AMABIS \& MARTHO, 2006, p. 324).

0 esquema abaixo representa a aquisição de estruturas na evolução das plantas. Os ramos correspondem a grupos de plantas representados, respectivamente, por musgos, samambaias, pinheiros e gramíneas. Os números I, II e III indicam a aquisição de uma característica: lendo-se de baixo para cima, os ramos anteriores a um número correspondem a plantas que não possuem essa característica e os ramos posteriores correspondem a plantas que a possuem.

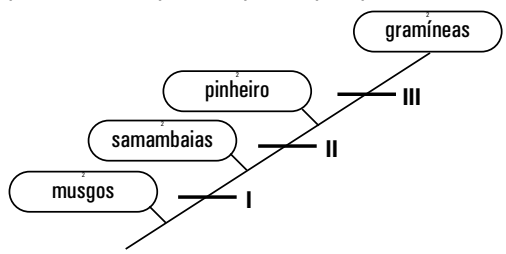

As características correspondentes a cada número estão corretamente indicadas em:

\begin{tabular}{l|l|l|l} 
a) & $\begin{array}{l}\text { I } \\
\text { presença de vasos } \\
\text { condutores de seiva }\end{array}$ & $\begin{array}{l}\text { II } \\
\text { formação de sementes }\end{array}$ & $\begin{array}{l}\text { III } \\
\text { produção de frutos }\end{array}$ \\
\hline b) & $\begin{array}{l}\text { presença de vasos } \\
\text { condutores de seiva }\end{array}$ & produção de frutos & formação de sementes \\
\hline c) & formação de sementes & produção de frutos & $\begin{array}{l}\text { presença de vasos } \\
\text { condutores de seiva }\end{array}$ \\
\hline d) & formação de sementes & $\begin{array}{l}\text { presença de vasos } \\
\text { condutores de seiva }\end{array}$ & produção de frutos \\
\hline e) & produção de frutos & formação de sementes & $\begin{array}{l}\text { presença de vasos } \\
\text { condutores de seiva }\end{array}$
\end{tabular}


Apesar de, no livro B, quase não abordar o assunto, ele contém atividades, na seção voltada ao vestibular, abordando relações evolutivas de plantas e animais (Figura 2). Essas atividades podem instigar o aluno a buscar mais informações junto ao professor e/ou em outros materiais.

Figura 2 - Atividade com abordagem da filogenia (LAURENCE, 2005, p. 387).

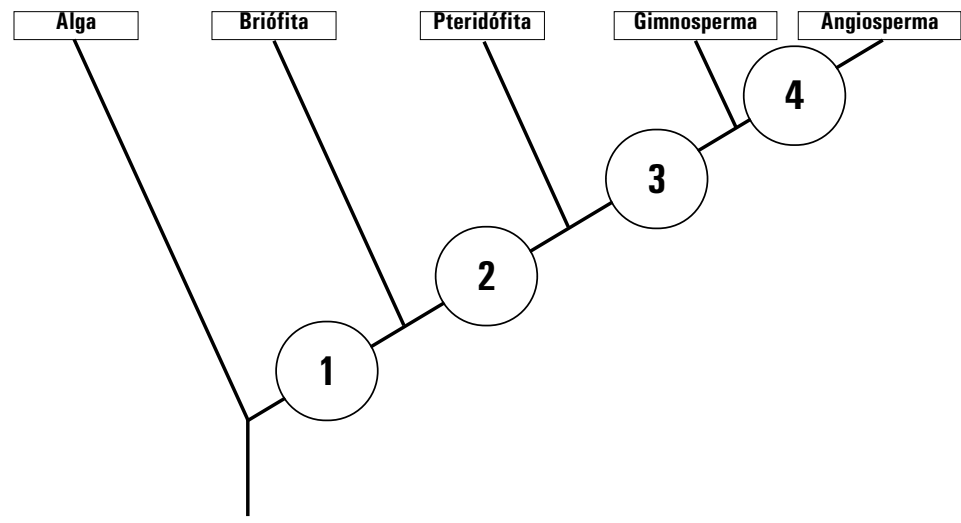

O diagrama anterior representa as relações filogenéticas entre as algas e os principais grupos de plantas atuais. Cada círculo numerado indica uma evolução aquisição evolutiva compartilhada apenas pelos grupos representados nos ramos acima desse círculo. Por exemplo, o círculo 1 representa

"embrião dependente do organismo genitor", caracter 'sitica comum a todos os grupos, exceto ao das algas. Os círculos de números 2, 3 e 4 representam, respectivamente:

a) alternância de gerações, fruto, semente.

b) alternância de gerações, tecidos condutores, fruto.

c) tecidos condutores, fruto, flor.

d) tecidos condutores, semente, fruto.

e) semente, flor, tecidos condutores.

O livro C propõe atividades ao final do capítulo 12, e em outros capítulos, mostrando a importância da compreensão da temática e fornecendo subsídios para que os alunos consigam voltar ao texto e responder os exercícios propostos, sendo alguns desses exercícios de vestibulares como podemos observar na Figura 3. O livro D aborda no texto a temática e não apresenta atividade relacionada à filogenética. O livro E não aborda a discussão da filogenia e, no decorrer dos capítulos, apresenta algumas atividades relacionadas como, por exemplo, um cladograma da evolução das plantas, sendo, portanto muito pouco explorado no decorrer do livro a temática de sistemática filogenética (Figura 4). 
Figura 3 - Atividade com abordagem da filogenia (LOPES; ROSSO, 2005, p. 250).

Considere o seguinte esquema, que representa critérios de classificação dicotômica de alguns grupos de seres vivos:

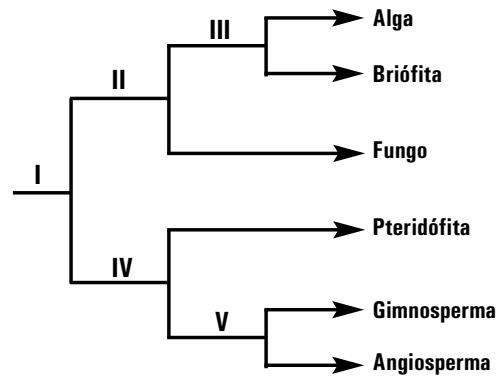

Analise as informações:

I. 0 líquen é exemplo de briófita.

II. A presença de vasos condutores de seiva permitiu que pteridófitas alcançassem maior crescimento e complexidade estrutural.

III. As gimnospermas são plantas cujas sementes não estão envolvidas por frutos.

Identifique a alternativa correta:

a) Apenas a afirmação l é verdadeira.

b) Apenas a afirmação II é verdadeira.

c) Apenas as afirmaç̃ões II e III são verdadeiras.

d) Apenas a afirmação III é verdadeira.

e) As afirmações I, II e III são verdadeiras.

Figura 4 - Atividade com abordagem da filogenia. (FAVARETO; MERCADANTE, 2005, p. 326).

\begin{abstract}
Você deve ter percebido, na questão anterior, que o passo 3 do diagrama poderia fazer referência a uma característica exclusiva dos nematelmintos, já que eles estavam como o ramo mais derivado do cladograma.

Considere agora novos passos do cladograma - 4, 5 e 6 - que representam características exclusivas, que surgiram na evolução de apenas um dos filos. Que características poderiam substituir corretamente 4, 5 e 6 ?
\end{abstract}

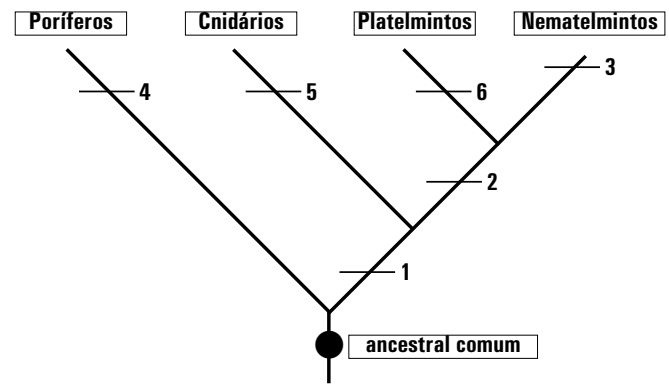

As atividades propostas pelos livros didáticos, quando bem elaboradas, são importantes, pois possibilitam ao aluno refletir sobre os conteúdos abordados em sala, podendo ser utilizadas pelo professor de acordo com os seus objetivos educacionais. 


\subsection{Uso de imagens}

O livro A apresenta figuras de cladogramas com imagens coloridas e bem distintas. Há legendas explicativas em todas as imagens. Há referências às imagens no decorrer do texto como exemplos explicativos, por exemplo, a Figura 5.

Figura 5 - Relação de parentesco entre alguns grupos de mamíferos (AMABIS; MARTH0, 2006, p. 240).

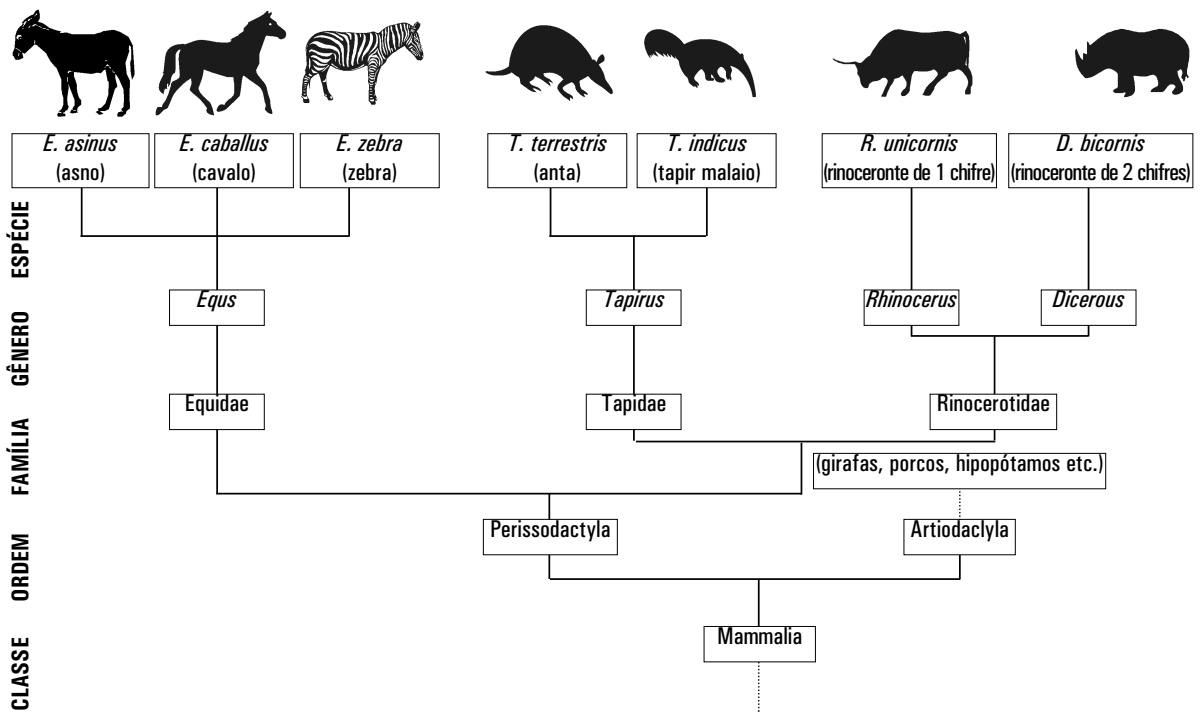

O livro B não apresenta nenhuma imagem acompanhando os textos, somente nas atividades alguns clados, em preto e branco, sendo pouco chamativos. O livro $C$ apresenta imagens e cladogramas no decorrer do texto de uma forma que auxilia no entendimento e na compreensão do tema abordado, com legendas e imagens coloridas. Os autores, em vários capítulos, voltam a utilizar cladogramas para exemplificar alguns assuntos, tais como: Propostas das relações filogenéticas dos fungos (Figura 6), divisão das plantas, o filo dos artrópodes e dos cordados com a provável relação com os equinodermos, também a divisão dos vertebrados e a relação dos répteis com as aves. Trazendo, portanto aos alunos uma visão ampla da sistemática e filogenia. 
Figura 6 - Cladograma mostrando uma das propostas de relações filogenéticas dos fungos (LOPES; ROSSO, 2005, p. 250).

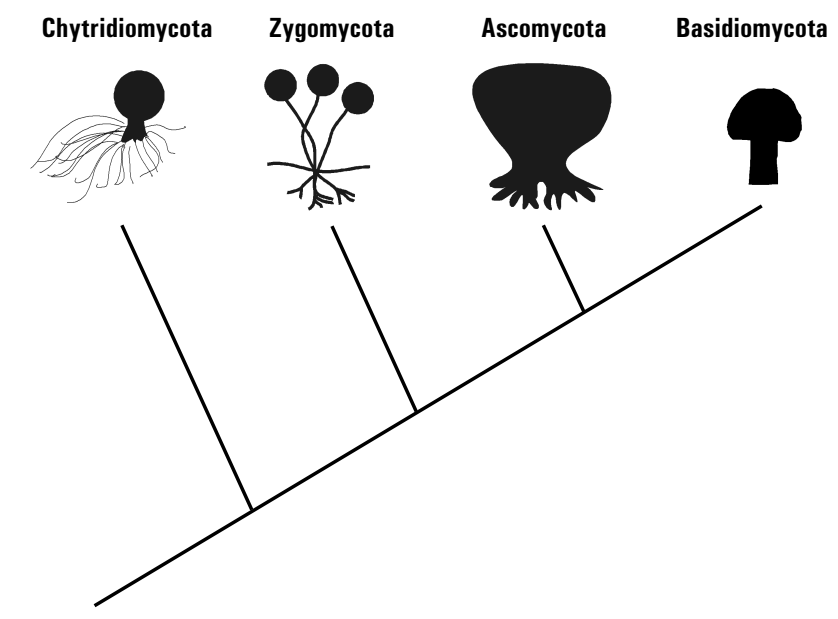

O livro D traz somente duas figuras relacionadas à nossa discussão, um cladograma exposto de uma forma simples com uma legenda e um quadro com a classificação tradicional o que é considerado pouco em relação à complexidade do tema. O livro E também apresenta poucas figuras relacionadas à filogenia. Um dos exemplos é a classificação dos animais segundo sua estrutura e organização corporal (Figura 7).

Figura 7 - Representação esquemática (sem escala) da classificação animal segundo a estrutura e a organização corporal (FAVARETO; MERCADANTE, 2005, p. 210).

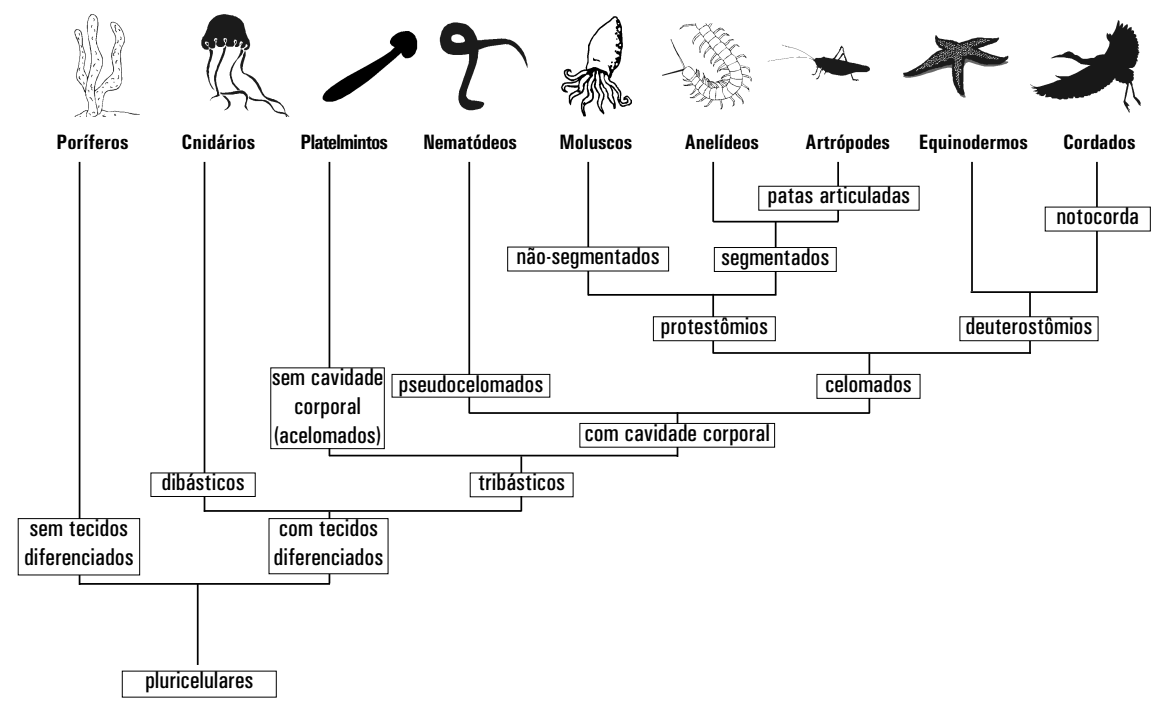


Como podemos perceber os livros B, D e E quase não possuem imagens sobre a temática abordada, segundo Freitas e Bruzzo (1999), as imagens são muito significativas para o aprendizado dos conhecimentos biológicos, pois, além de não serem apenas detalhes, as imagens permanecem na memória visual, muitas vezes substituindo o texto, que foi esquecido. Belmiro (2000) ainda salienta que, além de ilustrar, nomear e descrever, as imagens atuam como catalisadores, permitindo-se fazer destacar a razão interna, facilitando, assim, a aprendizagem. Para a autora, a importância das imagens no processo de ensino e aprendizagem é ressaltada também nos critérios de avaliação dos livros didáticos propostos pelo MEC para o Ensino Fundamental.

\subsection{Abordagem da história da Ciência}

Quanto à abordagem da história da Ciência para o acontecimento dos fatos, o livro A, sempre que possível, a menciona. Tanto como curiosidade quanto para auxiliar no entendimento do conteúdo, colocando-o de forma clara. No mesmo livro a história é retomada em três momentos, de forma simples para complementar ou exemplificar o texto. É o caso de: "Em seu livro Systema naturae, publicado em 1735, Lineu apresentou um sistema eficiente para dar nome aos seres vivos, isto é, uma nomenclatura biológica, que foi amplamente aceita pelos cientistas [...]". (AMABIS; MARTHO, 2006, p. 238).

No livro B só encontramos duas linhas que faz menção a um único trecho da história, deixando explícito como se fosse o único: "A proposta da nomenclatura binomial partiu do sueco Carolus Linnaeus (1707-1778) e é até hoje a forma adotada". (LAURENCE, 2005, p. 223).

No final do capítulo, o livro $\mathrm{C}$ traz um texto para discussão, retratando a história dos estudos acerca dos grupos de seres vivos de forma dinâmica e interessante com figuras e cladogramas para retratar, desde o início até os dias de hoje, como era e como é a classificação dos seres vivos e como os pesquisadores chegaram aos grupos atuais. Verifica-se isso em:

Começou a mudar em 1858 quando dois pesquisadores ingleses, Charles Darwin (1809-1882) e Alfred Russel Wallace (1823-1913), atuando de forma independente, revolucionaram a Biologia com a divulgação de ideias sobre evolução por seleção natural [...]. (LOPES; ROSSO, 2005, p. 180)

Desde os tempos de Aristóteles e posteriormente de Lineu até meados do século XX, costumava-se classificar os seres vivos em dois reinos: o Reino Plantae (Reino Vegetal ou reino das plantas) e o Reino Animalia (Reino Animal). (LOPES; ROSSO, 2005, p. 186). (início do texto para discussão no final do capítulo)

No livro D a abordagem histórica também foi utilizada de forma breve, somente citando dois momentos históricos, retratando a vida e o contexto científico dos trabalhos de Lineu e Darwin, em: 
O fundador da taxonomia foi o médico sueco Carl Von Linné (1707-1778) [...] aceitava a teoria fixista, isto é acreditava que as espécies não evoluíam. A ideia da evolução somente seria divulgada e aceita no século XIX, cerca de cem anos depois, com o trabalho de Charles Darwin (naturalista inglês, 1809-1882). (LINHARES; GEWANDSZNAJDER, 2005, p. 139)

O livro E não faz menção, em qualquer dos capítulos, a fatos históricos. Embora o pouco espaço destinado à inclusão de episódios históricos nos livros analisados, salienta-se que, mediante a abordagem da história da Ciência, conforme Martins (1998), pode se oportunizar a desmistificação do conhecimento científico, mostrando a dinâmica da construção científica.

\section{CONSIDERAC̣ÕES FINAIS}

Ao analisarmos a amostra de livros selecionados para esta investigação, verificamos que o assunto sistemática e filogenética nos livros A e C atende aos critérios utilizados, apresentando uma preocupação em introduzir a sistemática e filogenética no ensino. Percebemos nesses livros que os autores procuram colocar definições e explicações de cada assunto abordado, utilizando imagens e recuperando momentos históricos para um melhor entendimento do assunto. Os termos e definições utilizadas pelos autores, quando comparadas ao livro texto base, também estavam corretos, os exercícios de vestibular possibilitavam aos alunos a contextualização de seus conhecimentos, assim como textos complementares e algumas inferências sobre filogenias em alguns conteúdos, também essenciais para o melhor desenvolvimento desse tema para o ensino. No entanto, notamos a ausência de uma ligação filogenética entre os grupos, que são tratados de maneira separada como se fossem independentes um do outro, ou seja, os filos são abordados de maneira isolada como se não mantivessem nenhuma relação com os demais.

Em todos os livros analisados cada filo ou divisão foi enfocado de modo tradicional, quando se refere à filogenia a mesma é tratada brevemente no meio do capítulo e sem ligação, o que foge dos indicativos propostos por Amorim (1997) e Guimarães (2005). A vantagem do uso da sistemática filogenética seria, em princípio, permitir uma abordagem comparativa da vida e diminuir a distância entre os seres vivos, fornecendo subsídios para a compreensão da diversidade biológica. Assim, bastaria saber quando determinados caracteres surgiram, ao invés de memorizar todos os caracteres de todos os grupos, como se não houvesse qualquer ligação entre eles.

Nos demais livros analisados B, D e E o assunto sistemática e filogenética não é abordado de forma sistemática, nem mesmo dentro de um capítulo introdutório, fazendo com que o professor ao utilizar esse material tenha que contextualizar a temática, para possibilitar uma abordagem evolutiva dos conteúdos biológicos. Para Lobato et al (2009), mesmo não sendo possível tratar os 
temas de maneira muito aprofundada no Ensino Médio, também não se deveria simplificá-lo tanto, como vem sendo feito em alguns livros didáticos desse nível de ensino. Essa visão crítica sobre o material didático que será utilizado no ensino deve ser cada vez mais acentuada. O livro didático possui uma presença marcante nas salas de aula e isto se deve ao fato de que é um dos principais materiais impressos que os alunos de escolas brasileiras têm acesso. Portanto, ao adotar um livro o professor deve analisá-lo previamente, não só para verificar a existência de erros, mas também para certificar-se acerca dos objetivos do autor e se os seus objetivos são os mesmos. (ALVARES, 1991).

Cabe ao professor selecionar os aspectos que julgar mais adequados ao seu programa de ensino e tratá-los de forma integrada. (BATISTETI; ARAUJO; CALUZI, 2010). Atualizações e reparos devem ser constantes nos livros didáticos, pois grandes e valiosas ferramentas estão disponíveis, bastando para isso um maior comprometimento para essa empreitada, por parte de autores e professores.

No entanto, mais estudos devem ser realizados para verificar o quanto é significativo e importante para os alunos aprenderem Zoologia e Botânica com a sistemática filogenética como eixo integrador desses conteúdos. Defendese que essa abordagem metodológica permite ao aluno estudar os grupos de seres vivos como algo relacionado, permitindo-lhes uma melhor compreensão da biodiversidade e dos processos evolutivos. 


\section{NOTAS}

1 Sistemática é o estudo da diversidade de organismo e das relações entre eles, incluindo a taxonomia que é o estudo da classificação dos seres vivos.

2 A Filogenia trata da história evolutiva de um grupo, incluindo as relações de parentesco entre suas espécies ancestrais, e as espécies descendentes.

3 Como monofilético considera-se o grupo de seres vivos que reúne uma espécie ancestral e todos seus descendentes.

4 A Origem das Espécies (em inglês: On the Origin of Species), publicado em 1859, pelo naturalista britânico Charles Darwin, é um livro importante na história da Ciência, apresentando a Teoria da Evolução, base de toda Biologia Moderna.

\section{REFERÊNCIAS BIBLIOGRÁFICAS}

ALVARES, B. A. Livro didático: análise e seleção. In: MOREIRA, M. A.; AXT, R. (orgs.). Tópicos em ensino de Ciências. Porto Alegre: Sagra, 1991. p. 18-46.

AMABIS, J. M.; MARTHO, G. R. Fundamentos da Biologia Moderna. 4 ed. São Paulo: Moderna, 2006. AMORIM, D. S. Elementos básicos de sistemática filogenética. Ribeirão Preto: Holos, 1997.

AMORIM, D. S. Fundamentos de sistemática filogenética. Ribeirão Preto: Holos, 2005.

AMORIM, D. S. et al. Diversidade biológica e evolução: uma nova concepção para o ensino de Zoologia e Botânica no $2^{\circ}$ Grau. In: BARBIERI, M. R. (orgs.). A construção do conbecimento do professor: uma experiência de parceria entre professores do Ensino Fundamental e Médio da Rede Pública e a Universidade. Ribeirão Preto: Holos /FAPESP, 2001. p. 41-49.

BATISTETI, C. B. et al. A abordagem histórica do sistema de grupo sanguíneo ABO nos livros didáticos de Ciências e Biologia. ENCONTRO NACIONAL DE PESQUISA EM EDUCAÇÃO EM CIÊNCIAS, 6, 2007. Florianópolis. Anais... Florianópolis: Associação Brasileira de Pesquisa em Educação em Ciências, 2007. 1 CD-ROM.

BARDIN, L. Análise de conteúdo. Lisboa: Edição 70, 2000.

BATISTETI, C. B; ARAUJO, E. S. N. N; CALUZI, J. J. Os experimentos de Griffith no ensino de Biologia: A transposição didática do conceito de transformação nos livros didáticos. Revista Ensaio Pesquisa em Educaşão em Ciências, v. 12, n. 1, p. 83-99, 2010. Disponível em:

<http://www.portal.fae.ufmg.br/seer/index.php/ensaio>. Acesso em: 10 set. 2010.

BELMIRO, C. A. A imagem e suas formas de visualidade nos livros de português. Revista Educaşão \& Sociedade, Belo Horizonte, n. 72, p. 11-30, ago. 2000.

BRASIL. Ministério da Educação, Secretaria de Educação Média e Tecnológica. Parâmetros Curriculares Nacionais: Ensino Médio. Brasília: MEC/SEMTEC, 2002.

BRASIL. Ministério da Educação, Secretaria de Educação Básica. Biologia: catálogo do Programa Nacional do Livro para o Ensino Médio, PNLEM/2009. Brasília: Fundo Nacional de Desenvolvimento da Educação, 2009.

DONOGHUE, M. J; KADEREIT, J. W. Walter Zimmerman and the growth of phylogenetic theory. Systematic Biology, v. 41, n. 1, p 74-84, 1992.

DUPRÉ, J. Hidden treasure in the linnean hierarchy. Biology and Philosophy, v. 11, p. 423-433, 2002. ERESHEFSKY, M. The evolution of the linnaean hierarchy. Biology and Philosophy, v. 12, p. 492519, 1997.

FAVARETTO, J. A; MERCADANTE, C. Biologia. São Paulo: Moderna, 2005.

FRANCALANZA, H; AMARAL, I. A; GOUVEIA, M. S. F. O ensino de Ciências no Primeiro Grau. 14 ed. São Paulo: Atual, 1986.

FREITAS, D. S.; BRUZZO, C. As imagens nos livros didáticos de biologia. In: Encontro Nacional de Pesquisa em Educaşão em Ciências, 1999. Valinhos. Atas. São Paulo: ABRAPEC, 1999. CD -ROM. FREITAS, E. O.; MARTINS, I. Concepções de saúde no livro didático de Ciências. Revista Ensaio Pesquisa em Educação em Ciências, v. 10, n. 2, p. 222-248, 2008.

GIANNOTTI, S. M. O ensino de Matemática e o livro didático na voz dos professores: um estudo de caso. 2002. 
132 f. Dissertação (Mestrado em Educação) - Programa de Pós-Graduação em Educação. Universidade Estadual de Londrina, Londrina, 2002.

GUIMARÃES, M. A. Uma proposta de ensino de Zoologia baseada na sistemática filogenética. ENCONTRO NACIONAL DE DIDÁTICA E PRÁTICA DE ENSINO, 12, 2004, Curitiba. Anais... Curitiba: PUC-PR, 2004. p. 1074-1084.

GUIMARÃES, M. A. Cladogramas e evolução no ensino de Biologia. 2005. 233 f. Dissertação (Mestrado em Educação para Ciência) - Universidade Estadual Paulista - UNESP, Bauru, 2005.

HENNIG, W. Phylogenetic systematics. Urbana, IL: University of Illinois Press, 1966.

HENNIG, W. Cladistic analysis or cladistic classification? a reply to Ernst Mayr. Systematic Zoology, n. 24, p. 244-256, 1975.

HULL, D. L. The role of theories in biological systematics. Studies in the History and Philosophy of Biological and Biomedical Sciences. v. 32, n. 2, p. 221-238, 2001.

HULL, D. L. Science as a processes. Chicago: University of Chicago Press, 1988.

KRASILCHIK, M. Prática de ensino de Biologia. São Paulo: EDUSP, 2005.

LAURENCE, J. Biologia. São Paulo: Nova Geração, 2005.

LIMA, M. R. Construção e validação de instrumento de avaliação do livro didático de estudos sociais. Tecnologia Educacional, n. 60, p. 57-68, 1984.

LINHARES, S.; GEWANDSZNAJDER, F. Biologia. São Paulo: Ática, 2005.

LOBATO, A. C.; SILVA, C. N; LAGO, R. M; CARDEAL, Z. L.; QUADROS, A. L. Dirigindo o olhar para o efeito estufa nos livros didáticos do Ensino Médio: é simples entender esse fenômeno? Revista Ensaio Pesquisa em Educação em Ciências, v. 11, n. 1, p. 7-22, 2009. Disponível em: $<$ http://www.portal.fae.ufmg.br/seer/index.php/ensaio>. Acesso em: 12 ago. 2010.

LOPES, S; ROSSO, S. Biologia. São Paulo: Saraiva, 2005.

LOPES, W. R.; FERREIRA, M. J. M.; STEVAUX, M. N. Proposta pedagógica para o Ensino Médio: filogenia de animais. Revista Solta a Voz, v. 18, n. 2, 2007.

LOPES, W. R.; ROSA, S.A.; RODRIGUES, O. D.; BARBOSA, A. G. P.; STEVAUX, M. N. P. Filogenia dos animais: uma proposta para o ensino de Zoologia no Ensino Fundamental. CONGRESSO BRASILEIRO DE ZOOLOGIA, 25, 2004, Brasília. Resumos.., Brasília: p. 458. 2004.

MALLET, J.; WILLMOTT, K. Taxonomy: renaissance or tower of babel. Trends in ecology and evolution, v. 18, n. 2, p. 57-59, 2003.

MARTINS, R. A. Sobre o papel da história da Ciência no ensino. Revista da Sociedade Brasileira de História da Ciência, v. 1, n. 9, p. 3-5, 1990.

MARTINS, L. A-C. P. A história da Ciência e o ensino de Biologia. Ciência e Ensino, n. 7, p. 18-21, 1998. MAYR, E. O desenvolvimento do pensamento biológico. Brasília: UNB, 1998.

MOORE, J. Uma introdução aos invertebrados. São Paulo: Santos, 2003.

MOREIRA, M. A.; AXT, R. Ênfases curriculares e ensino de Ciências. In: MOREIRA, M. A.; AXT, R. (Orgs). Tópicos em ensino de Ciências. Porto Alegre: Sagra, 1991.

SCHUCH, L. M. M: SOARES, M. B. Oficina de classificação: de pokemons e infoartrópodos à sistemática filogenética. Cadernos do Aplicação, UFRGS, Porto Alegre, v. 16, n. 1, p. 9-18, 2003.

SILVA, E. R. L.; ALVES, L. F. A.; GIANNOTTI, S. M. Análise do conteúdo de artrópodes em livros didáticos de Biologia do Ensino Médio e o perfil do professor: estudo de caso1. Revista Varia Scientia, v. 6, n. 11, p. 83-98, 2006. 